\title{
THE HIGH-POWER S-BAND FEED SUBSYSTEM FOR THE ADVANCED PHOTON SOURCE INJECTOR TEST STAND*
}

\author{
A.E. Grelick ${ }^{\dagger}$, S. Berg, G. Goeppner, J. Lewellen, S. Milton, A. Nassiri, G. Pile, T. Smith \\ Advanced Photon Source, Argonne National Laboratory, Argonne, IL
}

\begin{abstract}
The rf subsystem for the Advanced Photon Source injector test stand is a totally passive system. Waveguide variable power dividers and phase shifters, which are pressurized with SF6, are used to provide three highpower ports that are independently adjustable in phase and amplitude while maintaining negligible differential phase jitter. Either three independent devices or a device requiring three inputs can be tested at any one time.
\end{abstract}

\section{INTRODUCTION}

The Advanced Photon Source (APS) is a highbrightness, third-generation light source user facility. In addition to providing brilliant $\mathrm{x}$-ray beams to our user community, we are actively engaged in research toward fourth-generation linac-based light sources [1]. The former activity requires a consistent, reliable, and stable electron beam source for storage-ring injection. The latter requires high-performance, state-of-the-art electron gun technology.

In order to support these two areas of activity, an rf test area is currently under construction at the APS linac [2]. The initial implementation allows for the repair and characterization of both the existing [3,4] APS main injector electron guns and new guns using an upgraded design [5]. Testing of guns incorporating up to three cavities has already been planned [6]. Therefore, we established a requirement for three rf output ports with each port having independently adjustable phase and amplitude to support more complex experiments or simultaneous testing of multiple rf devices.

\section{CONFIGURATION}

\subsection{General}

The key components incorporated in the feed subsystem are variable waveguide phase shifters built with side-wall hybrids and paired, non-contacting shorts, which are movable under stepper-motor control. Variable power dividers are built by adding two additional side-wall hybrids to a phase shifter. Four-port, differential-phaseshift circulators configured as isolators direct any gunreflected power to air- or water-cooled loads and away from the variable power dividers and phase shifters. All these

* This work is supported by the US Department of Energy,

Office of Basic Energy Science, under Contract No. W-31-

109-ENG-38.

$\dagger$ Corresponding author, grelick@aps.anl.gov components are commercially available and are built using WR284 waveguide pressurized with SF6 at 30 psig.

A waveguide window is used in each output line to isolate the SF6 from the vacuum environment of the gun under test. Each window is followed by a bidirectional loop coupler, which provides monitoring of forward and reflected power.

All components in the rf path are passive. Short-term variations in relative power and phase between any two of the output ports is expected to be vanishingly small.

\subsection{Waveguide Environment}

The use of waveguide that is pressurized with SF6 at the input to the feed subsystem was predetermined by the decision to use reworked, commercially available waveguide switches [7]. A pressure of 30 psig was selected as the start of diminishing returns in terms of breakdown threshold versus pressure. Because the circulators must also be operated in a pressurized environment, the location of each waveguide window was chosen to be immediately following the corresponding circulator. The bidirectional loop couplers therefore are the only subsystem components implemented entirely using waveguide that is under vacuum.

\subsection{Topology}

A block schematic diagram of the rf paths is shown in Fig. 1. There are two waveguide switches at the input to the subsystem. The first switch directs rf power either to the photocathode gun used for linac research activities or to the test area. The second switch provides redundancy, so that removal of power from the test area can be confirmed with the extremely high confidence required for personnel safety. Two variable power dividers permit individual adjustment of the power at each output port. Variable phase shifters in two of the paths permit individual adjustment of the phase at each output port. The path to each port includes an isolator, a waveguide window, and a bidirectional loop coupler with a directivity of at least $30 \mathrm{~dB}$. 


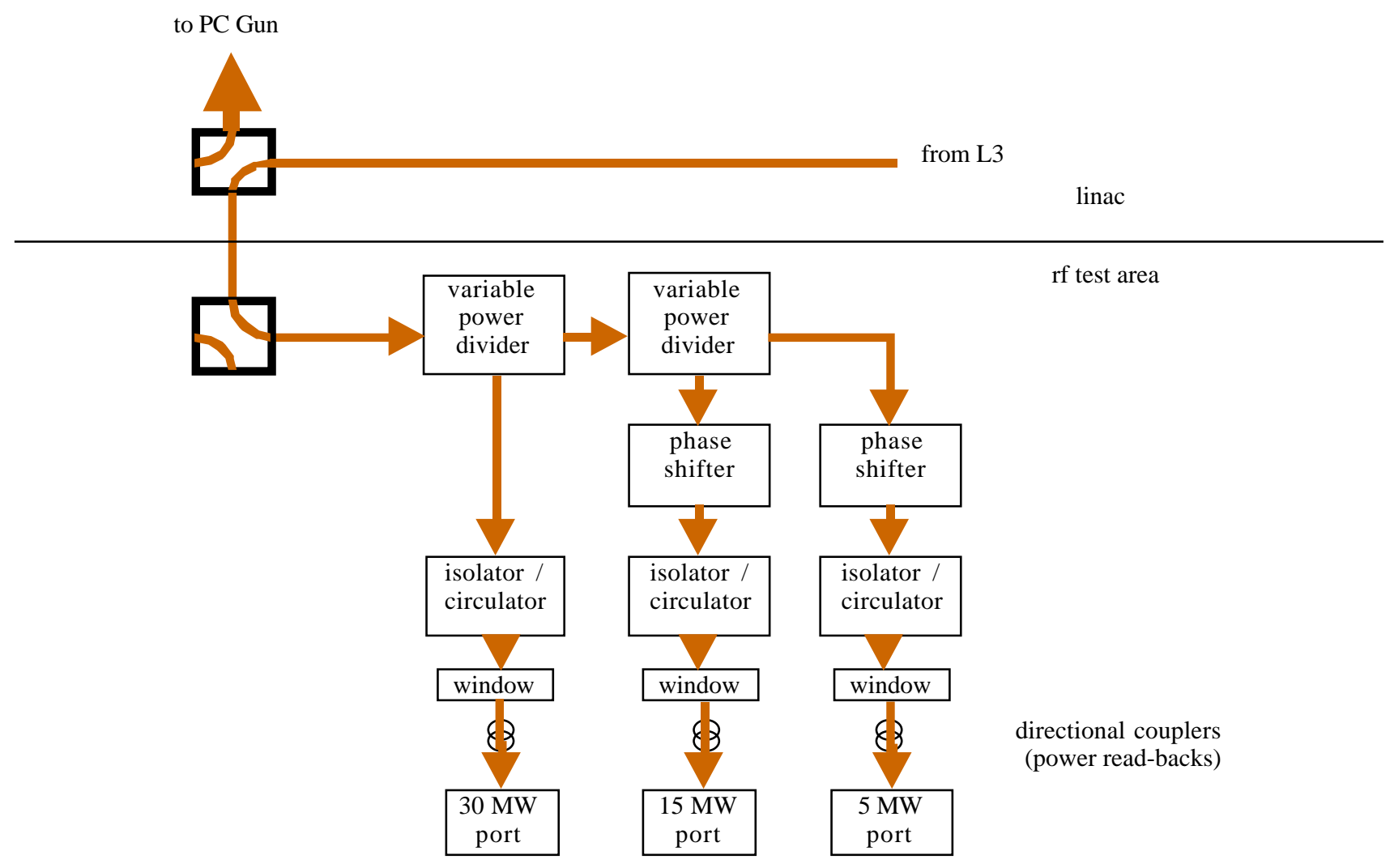

Figure 1: S-band feed subsystem configuration.

\subsection{Power Handling}

Any of the components can potentially become the practical limitation on power handling capability.

The variable phase shifters, both where used directly and as sub-components of the variable power dividers, are especially notable here because of the standing wave conditions produced by their internal sliding shorts. The region of a short must be restricted to one fourth of the normal waveguide peak power. The direct phase shifters apply one-half of the incident power to each of the two sliding shorts while the variable power dividers apply onefourth of the incident power to each of the two sliding shorts. Therefore, it can be seen that a variable power divider can handle the full waveguide power while a phase shifter is restricted to one-half of the full waveguide power. Testing [8] has established $30 \mathrm{MW}$ as a safe, real working power in pressurized WR284.

The power rating of the circulator is another constraint. Two 35-MW rated circulators and one 5-MW rated circulator are available for this installation.

Combining the restrictions, there is one port with up to $30 \mathrm{MW}$ available, a second port with up to $15 \mathrm{MW}$ available, and a third port with up to $5 \mathrm{MW}$ available. An additional constraint is that the sum of the power at the three ports cannot exceed $30 \mathrm{MW}$.

\subsection{Layout Considerations}

The small size and restricted conditions in the room reserved as the test area mean that the waveguide must be ceiling mounted and fold back on itself. These constraints have resulted in a dense, three-level layout, which is shown in Fig. 2.

\section{STATUS AND PLANS}

A single-port subsystem has been installed and checked out. It is expected to become operational very soon. Major components for the full version are on order. Completion of the layout is awaiting scheduling.

\section{ACKNOWLEDGMENTS}

The authors wish to thank M. Givens for modeling assistance; J. Gagliano, J. Hoyt, A. Lopez, M. Martens, W. Michalek, V. Svirtun, and R. Wilson for fabrication, leak checking, and assembly of waveguide; W. Yoder and D. Meyer for checkout of the initial version of the subsystem; and C. Eyberger for editorial assistance. 


\section{REFERENCES}

[1] S.V. Milton et al., "Observation and Analysis of Self-Amplified Spontaneous Emission at the APS Low-Energy Undulator Test Line," Science (published initially in Science Express Online, 17 May 2001).

[2] J.W. Lewellen et al., "The Advanced Photon Source Injector Test Stand," these proceedings.

[3] J.W. Lewellen et al., "Operation of the APS rf Gun," Proceedings of the XIX International Linac Conference, pp. 863-865 (1999).

[4] J.W. Lewellen et al., "A Hot-Spare Injector for the APS Linac," Proceedings of the 1999 Particle Accelerator Conference, Vol. 3, pp. 1979-1981 (1999).

[5] K. Beczek et al., "A Rationalized Approach to Thermionic RF Gun Design," these proceedings.
[6] J.W. Lewellen and S.V. Milton, "Preliminary Calculations of Ballistic Bunch Compression with Thermionic Cathode rf Guns," Proc. SPIE - Int. Soc. Opt. Eng. (Coherent Electron Beam X-Ray Sources: Techniques and Applications), Vol. 3154, pp. 162171 (1997).

[7] A.E. Grelick et al., "Testing and Implementation Progress on the Advanced Photon Source (APS) Linear Accelerator (Linac) High-Power S-band Switching System," Proceedings of the XX International Linac Conference, pp. 983-985 (2000).

[8] A. Nassiri, A. E. Grelick, R. L. Kustom, M. White, "High Peak-Power Test of S-Band Waveguide Switches," Proceedings of the 1997 Particle Accelerator Conference, Vancouver, BC, Canada (1998).

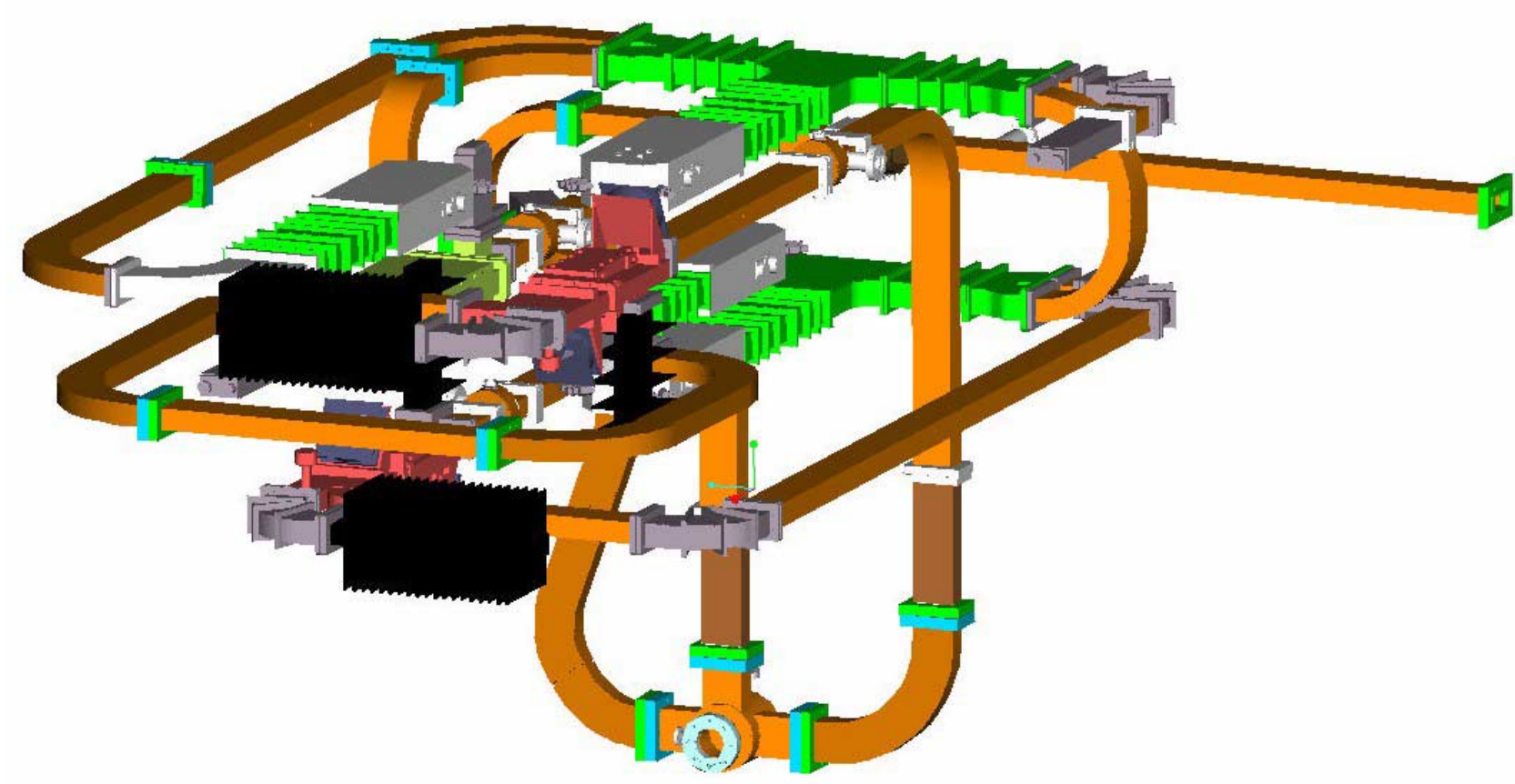

Figure 2: S-band feed subsystem layout 